A 67-year-old lady with anorexia had a percutaneous endoscopic gastrostomy (PEG) tube for long-term feeding. She also suffered from psoriasis. After 5 years the PEG was removed, but a month later she presented at the hospital with a productive cough and symptoms of air and fluid leakage from the old PEG site on coughing.

She was treated with antibiotics, but when the fistula failed to heal she underwent endoscopy in an attempt to close the fistula using clips. On endoscopy, a large opening on the body of the stomach was seen (Figure 1), and five Olympus HX600-135 clips were deployed internally on the fistula, using an Olympus GIF Q200 gastroscope. Closure was ascertained by air insufflation, which did not demonstrate leakage of air externally. On follow-up the fistula had completely healed (Figure $\mathbf{2}$ ).

A permanent gastrocutaneous fistula is a rare complication of PEG tube removal. Persistently leaking fistulas usually require surgical closure. However there have been other reports of successful nonsurgical treatment for enterocutaneous fistulas. Shandy et al. [1] described the use of endoscopically injected fibrin sealant to close a gastrocutaneous fistula,

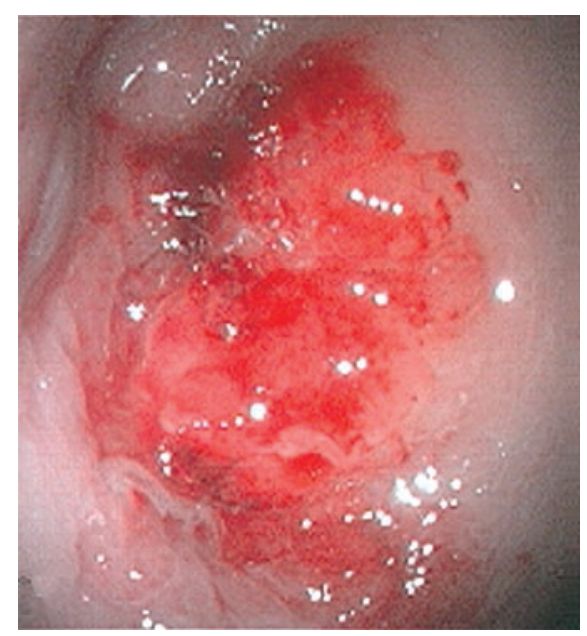

Figure 1 Endoscopic appearance of the fistula.

\title{
Endoscopic Clipping of a Nonhealing Gastro- cutaneous Fistula Following Gastrostomy Removal
}

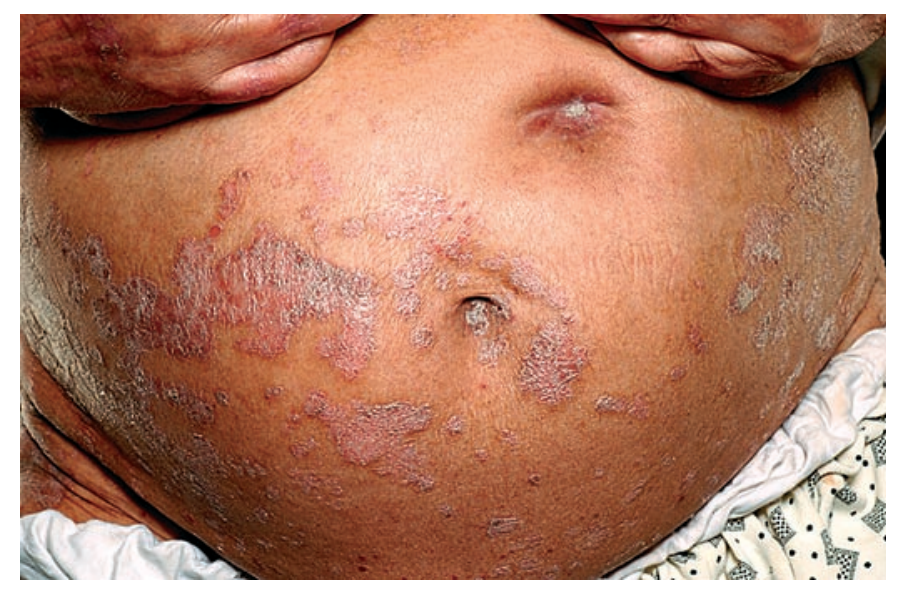

Figure 2 The healed fistula following endoscopic clipping.

and there are reports on the use of collagen plugs and Gelfoam pledgets [2-4].

Our patient had a PEG tube in place for 5 years, a persistent cough, and a number of local infections at the PEG site. Although she suffered from psoriasis, there is no evidence to suggest that psoriasis delays wound healing [5]. The most likely reason for the nonhealing of the fistula in this patient would be the presence of the cough, which mechanically disrupted plug formation. The successful management using clips endoscopically makes the case unique.

\section{P. Thurairajah, A. B. Hawthorne}

Department of Medicine and Gastroenterology, University Hospital of Wales, Cardiff, Wales, UK.

\section{References}

${ }^{1}$ Shand A, Pendlebury J, Reading Set al. Endoscopic fibrin sealant injection: a novel method of closing a refractory gastrocutaneous fistula. Gastrointest Endosc 1997; 46: $357-358$

${ }^{2}$ Lomis NNT, Miller FJ, Loftus TJet al. Refractory abdominal-cutaneous fistula or leaks: percutaneous management with a collagen plug. J Am Coll Surg 2000; 190: 588 - 5926
${ }^{3}$ Kim HS, Lee DK, Baik SK, Kwon SO. Endoscopic management of colocutaneous fistula after percutaneous endoscopic gastrostomy. Endoscopy 2002; 34: 430

${ }^{4}$ Markis J, Sheiman RG. Percutaneous treatment of a gastrocutaneous fistula after gastrostomy tube removal. J Vasc Intervent Radiol 2002; 13: 205-207

${ }^{5}$ Lynfield YL, Ostroff G, Abraham J. Bacteria, skin sterilization and wound healing in psoriasis. N Y State J Med 1972; $1247-1250$

\section{Corresponding Author}

\section{A. B. Hawthorne, M.D.}

University Hospital of Wales

Heath Park

Cardiff, CF14 4XW

UK

Fax: $\quad+44-2920-745131$

E-mail: Barney.Hawthorne@Cardiffand Vale.wales.nhs.uk 